\title{
(C) OPEN ACCESS \\ Leber congenital amaurosis/early-onset severe retinal dystrophy: clinical features, molecular genetics and therapeutic interventions
}

\author{
Neruban Kumaran, ${ }^{1,2}$ Anthony T Moore, ${ }^{1,2,3}$ Richard G Weleber, ${ }^{4}$ Michel Michaelides ${ }^{1,2}$
}

'UCL Institute of Ophthalmology, University College London, London, UK ${ }^{2}$ Moorfields Eye Hospital NHS Foundation Trust, London, UK ${ }^{3}$ University of California San Francisco, San Francisco CA, California, USA

${ }^{4}$ Casey Eye Institute, Oregon Health and Science University, Portland, Oregon, USA

\section{Correspondence to} Professor Michel Michaelides, UCL Institute of Ophthalmology, 11-43 Bath Street, London, EC1V 9EL, UK; Michel. Michaelides@moorfields.nhs.uk

Received 23 November 2016 Revised 26 April 2017

Accepted 30 April 2017 Published Online First 8 July 2017
CrossMark

To cite: Kumaran $\mathrm{N}$, Moore AT, Weleber RG, et al. Br J Ophthalmol

2017;101:1147-1154.

\begin{abstract}
Leber congenital amaurosis (LCA) and early-onset severe retinal dystrophy (EOSRD) are both genetically and phenotypically heterogeneous, and characterised clinically by severe congenital/early infancy visual loss, nystagmus, amaurotic pupils and markedly reduced/ absent full-field electroretinograms. The vast genetic heterogeneity of inherited retinal disease has been established over the last 10 - 20 years, with diseasecausing variants identified in 25 genes to date associated with LCA/EOSRD, accounting for $70-80 \%$ of cases, with thereby more genes yet to be identified. There is now far greater understanding of the structural and functional associations seen in the various LCA/EOSRD genotypes. Subsequent development/characterisation of LCA/EOSRD animal models has shed light on the underlying pathogenesis and allowed the demonstration of successful rescue with gene replacement therapy and pharmacological intervention in multiple models. These advancements have culminated in more than 12 completed, ongoing and anticipated phase I/II and phase III gene therapy and pharmacological human clinical trials. This review describes the clinical and genetic characteristics of LCA/EOSRD and the differential diagnoses to be considered. We discuss in further detail the diagnostic clinical features, pathophysiology, animal models and human treatment studies and trials, in the more common genetic subtypes and/or those closest to intervention.
\end{abstract}

\section{INTRODUCTION}

Inherited retinal disease (IRD) represents the second most common cause of legal blindness in childhood and the leading cause among the working aged population in England and Wales. ${ }^{1}$ Prior to identification of the causative genes, clinicians classified patients into groups based on Mendelian inheritance, age of onset and clinical features. The discovery of the underlying genetic causes over the last two decades has led to far greater understanding of disease mechanisms in IRD which has informed development of novel therapies, culminating in the first gene therapy trials for RPE65-associated Leber congenital amaurosis (LCA)/Early Onset Severe Retinal Dystrophy (EOSRD) in 2008..$^{2-4}$

LCA was first described by Theodore Leber in 1869 and is now used to describe a group of severe recessively inherited, early infantile onset rod-cone dystrophies..$^{5}$ In 1916, Leber described what he considered a milder form of the same disease $^{6}$ which has had several names, including
EOSRD, severe early childhood-onset retinal dystrophy (SECORD) ${ }^{7}$ and early-onset retinitis pigmentosa. Whereas LCA is congenital or presents within the first few months of life, is associated with nystagmus, poor pupil responses and in most instances an undetectable full-field electroretinogram (ERG); EOSRD/SECORD is defined as a severe retinal dystrophy presenting after infancy and usually before the age of 5 years. Other distinguishing features of EOSRD/ SECORD include better residual visual function and small ERG signals, particularly for the lesser-affected photoreceptor system. Of note, there is significant overlap between the molecular causes of LCA and EOSRD, with some genes causing both clinical phenotypes. However, certain genes are more frequently associated with LCA, for example, GUCY2D, NMNAT1, CEP290 and AIPL1, whereas mutations in others including RPE65, LRAT and RDH12, more commonly result in an EOSRD phenotype.

To date, mutations in 25 genes have been identified as causing LCA/EOSRD; most are expressed solely or predominantly in the retina or the retinal pigment epithelium (RPE). ${ }^{8}$ These genes have been shown to encode proteins with a diverse range of retinal functions, including phototransduction, the visual cycle and photoreceptor development/integrity (table 1 , figure 1 ). ${ }^{9-11}$

Given recent advances in understanding of the molecular basis of these disorders and the ongoing clinical trials of novel therapies, we herein review the clinical characteristics, animal models and pathophysiology of LCA/EOSRD, prioritising the more common genotypes and/or those closest to intervention.

\section{Clinical characteristics}

LCA/EOSRD has a prevalence between 1 in $33000^{12}$ to 1 in $81000,{ }^{13}$ and is believed to account for $\geq 5 \%$ of all IRD. ${ }^{12}$

LCA is associated with severe visual impairment from birth or the first few months of life accompanied by roving eye movements or nystagmus and poor pupillary light responses. Eye poking, the 'oculodigital' sign, is common. The ERG is undetectable or severely abnormal. Fundus examination may be normal at presentation, but a variety of abnormal fundus appearances may be present or develop over time, including disc pallor, vessel attenuation or mild peripheral pigmentary retinopathy. There may also be disc drusen, optic disc 


\begin{tabular}{|c|c|c|c|c|}
\hline Locus name & $\begin{array}{l}\text { Causative } \\
\text { gene }\end{array}$ & Protein & Protein function(s) & $\begin{array}{l}\text { Approximate } \\
\text { frequency }\end{array}$ \\
\hline LCA 1 & GUCY2D* & Guanylate cyclase-1 & Phototransduction & $10 \%-20 \%$ \\
\hline LCA 2 & RPE65† & Retinoid isomerase & Retinoid cycle & $5 \%-10 \%$ \\
\hline LCA 3 & SPATA7 & Spermatogenesis-associated protein 7 & Photoreceptor ciliary transport & $3 \%$ \\
\hline LCA 4 & AIPL1* & Aryl-hydrocarbon-interacting-protein-like 1 & Phototransduction/protein biosynthesis & $<5 \%$ \\
\hline LCA 5 & LCA5 & Libercilin & Photoreceptor ciliary transport & $1 \%-2 \%$ \\
\hline LCA 6 & RPGRIP1 & $\begin{array}{l}\text { Retinitis pigmentosa GTPase regulator-interacting } \\
\text { protein } 1\end{array}$ & Photoreceptor ciliary transport & $5 \%$ \\
\hline LCA 7 & $C R X$ & Cone-rod homeobox & Photoreceptor morphogenesis & $1 \%$ \\
\hline LCA 8 & $C R B 1 *$ & Crumbs homologue 1 & Photoreceptor morphogenesis & $10 \%$ \\
\hline LCA 9 & NMNAT1* & Nicotinamide nucleotide adenyltransferase1 & Coenzyme NAD biosynthesis & Unknown \\
\hline LCA 10 & CEP290 & Centrosomal protein $290 \mathrm{kDA}$ & Photoreceptor ciliary transport & $15 \%-20 \%$ \\
\hline LCA 11 & IMPDH1 & Inosine $5^{\prime}-$ monophosphate dehydrogenase 1 & Guanine synthesis & $5 \%$ \\
\hline LCA 12 & $R D 3$ & Protein RD3 & Protein trafficking & $<1 \%$ \\
\hline LCA 13 & RDH12† & Retinol dehydrogenase 12 & Retinoid cycle & $10 \%$ \\
\hline LCA 14 & LRAT† & Lecithin:retinol acyl transferase & Retinoid cycle & $<1 \%$ \\
\hline LCA 15 & TULP1 & Tubby-like protein & Photoreceptor ciliary transport & $<1 \%$ \\
\hline LCA 16 & KCNJ13 & Kir7 inwardly rectifying potassium channel & Phototransduction & Unknown \\
\hline \multirow[t]{9}{*}{ LCA 17} & GDF6 & Growth differentiation factor 6 & Photoreceptor morphogenesis & Unknown \\
\hline & OTX2 & Orthodenticle homeobox 2 protein & Photoreceptor differentiation & Unknown \\
\hline & CABP4 & Calcium-binding protein 4 & Phototransduction & Unknown \\
\hline & CLUAP1 & Clusterin associated protein 1 & Photoreceptor ciliary transport & Unknown \\
\hline & IQCB1 & IQ motif containing B1 protein & Photoreceptor ciliary transport & Unknown \\
\hline & DTHD1 & Death-domain containing protein 1 & Unknown & Unknown \\
\hline & IFT140 & $\begin{array}{l}\text { Intraflagellar transport } 140 \text { chlamydomonas } \\
\text { homologue protein }\end{array}$ & Photoreceptor ciliary transport & Unknown \\
\hline & ALMS1 & ALMS Protein & Photoreceptor ciliary transport & Unknown \\
\hline & PRPH2 & Perpherin & Photoreceptor outer segment structure/stabilisation & Unknown \\
\hline
\end{tabular}

${ }^{*}$ Genes associated with EOSRD.

tGenes more frequently associated with LCA.

Other genes have shown no clear predilection.

EOSRD, early-onset severe retinal dystrophy; LCA, Leber congenital amaurosis.

oedema or pseudopapilloedema, a flecked retina, maculopathy or nummular pigmentation (figure 2). Affected infants often have high hyperopia, or less commonly high myopia, suggesting impaired emmetropisation. ${ }^{14}$

The rate of loss of visual function and early childhood visual acuity vary markedly in patients with LCA/EOSRD, with certain genotypes (eg, GUCY2D and AIPL1-LCA) known to be more severe than others, with earlier more profound visual loss. Although visual outcome is variable, vision when the child is old enough to be reliably tested is in the region of $3 / 60$ to perception of light. Given the often severe and early visual loss, other areas of development including speech, social skills and behaviour may be delayed; early involvement of a specialist paediatrician with expertise in the developmental needs of children with visual impairment can significantly mitigate/delay disruption to these other fundamental areas of childhood development. $^{15}$

The identified genes account for approximately 70\%-80\% of LCA/EOSRD cases (table 1, figure 1 and below), with GUCY2D, CEP290, CRB1, RDH12 and RPE65 being the most common. ${ }^{9}{ }^{16-19}$ It has been possible to identify certain characteristic associated phenotypes (figure 2 and below): RDH12-associated disease, which gives rise to an EOSRD phenotype is characterised by early-dense intraretinal pigment migration pigmentation and maculopathy. CRB1-associated disease has nummular pigmentation, maculopathy, relative preservation of para-arteriolar RPE, with retinal thickening and loss of lamination on optical coherence tomography. TULP1, AIPL1 and NMNAT1-associated disease are also characterised by maculopathy which in the case of patients with NMNAT1 mutations is of early onset and extensive.

Most cases of LCA/EOSRD occur in otherwise normal infants and any non-ocular symptoms or signs should be investigated for syndromic retinal dystrophies or neurometabolic disease, usually in conjunction with a paediatrician. Renal involvement (nephronophthisis which can lead to end-stage renal failure) may be seen in some genetic subtypes of LCA/EOSRD (eg, IQCB1, IFT140 and CEP290) as part of syndromes including Senior-Loken Syndrome and Joubert Syndrome. ${ }^{20-22}$ Early molecular diagnosis can help prioritise which children should have ongoing systemic investigations.

The differential diagnosis of an infant with severe visual loss and nystagmus is broad and includes both syndromic and non-syndromic diseases (table 2). Conditions that are important to be distinguished from LCA/EOSRD include complete and incomplete Achromatopsia, S-cone monochromatism, complete and incomplete congenital stationary night blindness and albinism; however careful examination and detailed investigation including electrophysiology usually allow an accurate diagnosis to be established. Molecular genetic testing may then allow a more specific diagnosis (table 2). 


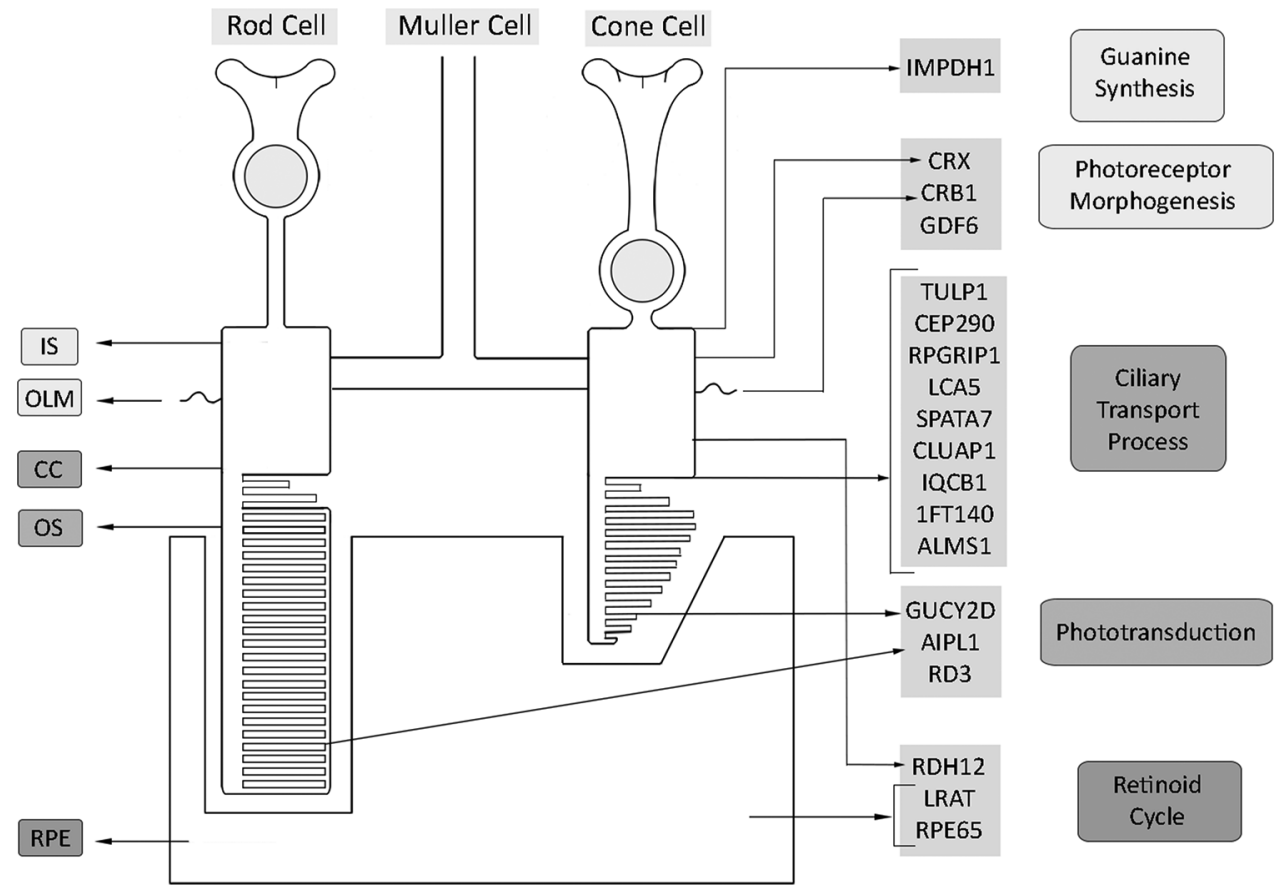

Figure 1 Spatial representation of expression of LCA/EOSRD genes, grouped according to their proposed function. EOSRD, early-onset severe retinal dystrophy; LCA, Leber congenital amaurosis.

\section{Selected specific genotypes \\ GUCY2D-associated LCA}

GUCY2D was the first gene to be associated with LCA/EOSRD and is one of the most common, accounting for approximately $10 \%-20 \%$ of cases. ${ }^{16} \mathrm{GUCY} 2 \mathrm{D}$ is known to encode retinal guanylate cyclase-1 (RetGC1), expressed in photoreceptor outer segments, to a greater degree in cones than rods. ${ }^{23}{ }^{24}$ RetGC1 is known to play an important role in photoreceptor recovery following phototransduction, thereby disease-causing variants in GUCY2D and subsequent RetGC1 deficiency result in the biochemical equivalent of chronic light exposure. ${ }^{16}$

Patients with GUCY2D-associated LCA often have relatively normal fundi, and also experience significant photophobia in contrast to most other LCA/EOSRD genotypes. There can be relatively preserved outer retinal / photoreceptor structure on optical coherence tomography (OCT) in many patients, although foveal cone outer segment abnormalities and foveal cone loss has been observed. ${ }^{25}$ In contrast to other forms of LCA/EOSRD which have a rod-cone dystrophy phenotype, in GUCY2D disease patients often retain substantial rod function, with a smaller subset having detectable but reduced cone function (ie, cone-rod disease), based on ERG, psychophysical assessments and vision-guided mobility testing. ${ }^{25}$ Due to the majority of patients lacking cone-mediated vision, patients often present with markedly reduced visual acuity and a lack of colour perception. ${ }^{27}$

Disease mechanisms and interventional approaches have been explored in several animal models of GUCY2D-LCA. Initially, gene replacement was investigated using an HIV1-based lentiviral vector in a naturally occurring chicken model and showed improved optokinetic reflexes and volitional visual behaviour. ${ }^{28}$ Subsequently, multiple groups have had therapeutic success in

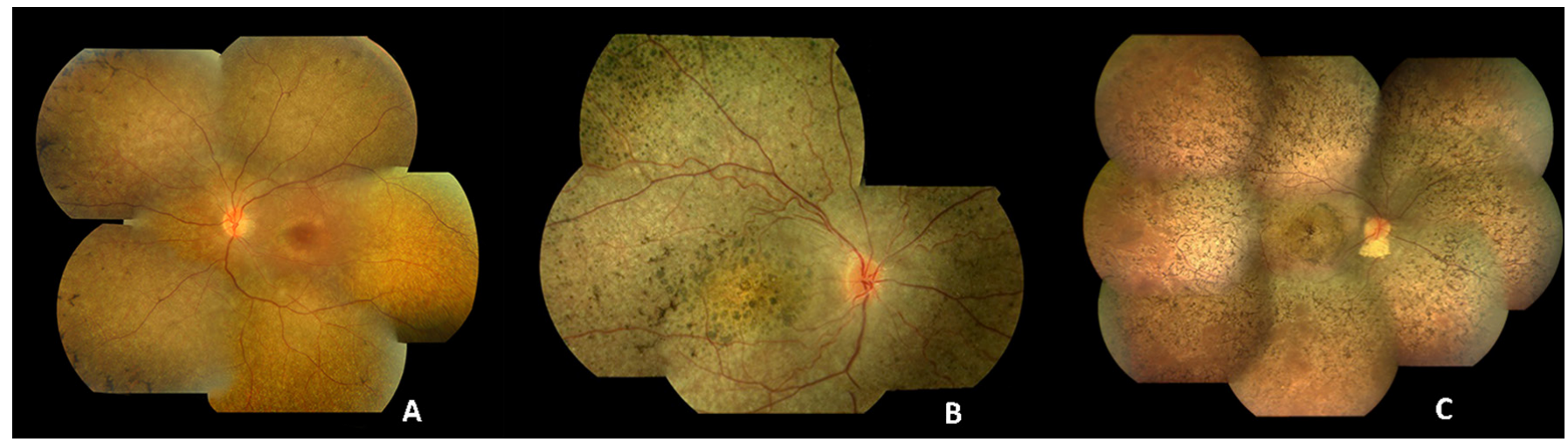

Figure 2 Colour fundus photographs of patients with recognisable LCA/EOSRD clinical phenotypes. (A) RPE65-retinopathy, associated with a blonde fundus, peripheral, white punctate lesions and normal central macular appearance in keeping with central preservation of outer retina. (B) CRB1-retinopathy characterised by nummular pigmentation, periarteriolar sparing of the RPE and macular atrophy. (C) RDH12-retinopathy with characteristic dense intraretinal pigmentation and macular atrophy with pigmentation and yellowing. EOSRD, early-onset severe retinal dystrophy; LCA, Leber congenital amaurosis; RPE, retinal pigment epithelium. 
Table 2 Selected conditions/syndromes to be considered in the differential diagnosis of isolated LCA/EOSRD

\begin{tabular}{ll}
\hline Condition/syndrome & Assessments and features that assist in distinguishing from LCA/EOSRD \\
\hline Achromatopsia & $\begin{array}{l}\text { Achromatopsia is characterised by absent/markedly reduced cone responses with normal rod ERG responses and a stationary natural } \\
\text { history; compared with the flat/markedly reduced full-field ERGs and progressive degeneration seen in LCA/EOSRD. }\end{array}$ \\
$\begin{array}{l}\text { Congenital stationary night blindness } \\
\text { Ocular and oculocutaneous albinism }\end{array}$ & $\begin{array}{l}\text { Can be differentiated on the basis of ERG phenotype and natural history. } \\
\text { Clinical examination (skin, hair, eyebrows/eyelashes; iris and retina), retinal imaging (OCT and FAF) and electrophysiological } \\
\text { assessment. }\end{array}$ \\
\hline Optic nerve hypoplasia & $\begin{array}{l}\text { Clinical examination and electrophysiological assessment. Of note, absent pupil reflexes suggests severe optic nerve hypoplasia } \\
\text { rather than LCA. }\end{array}$ \\
\hline Batten disease & $\begin{array}{l}\text { Infantile Neuronal Ceroid Lipofuscinosis (NCL) presents with congenital or early- onset blindness, with onset by age } 6 \text { months; } \\
\text { whereas patients with Late and Juvenile onset NCL present at 2-4 and 6years of age or older, respectively. Patients with NCL have } \\
\text { neurocognitive decline and can have epilepsy. }\end{array}$ \\
\hline Joubert syndrome & $\begin{array}{l}\text { Patients present with severe visual impairment, ocular motor abnormalities, often have the 'molar tooth' sign on MRI and develop } \\
\text { nephronophthisis in later childhood. }\end{array}$ \\
\hline Peroxisomal diseases & Associated features include sensorineural deafness, dysmorphic features, developmental delay, hepatomegaly and early death. \\
Alstrom syndrome & $\begin{array}{l}\text { Presents with infantile onset nystagmus, photophobia and a cone-rod dystrophy on electrophysiological assessment. Other systemic } \\
\text { features include childhood obesity, hyperinsulinaemia, type } 2 \text { diabetes mellitus, hepatic dysfunction, heart failure, sensorineural } \\
\text { hearing loss and renal failure. }\end{array}$ \\
\hline Cobalamin C deficiency & $\begin{array}{l}\text { Has a variable phenotype with severely affected individuals showing progressive, infantile onset, metabolic, neurological and } \\
\text { ophthalmic manifestations, including infantile nystagmus, bulls-eye maculopathy and reduced responses on ERG. }\end{array}$ \\
\hline
\end{tabular}

EOSRD, early-onset severe retinal dystrophy; FAF, fundus autofluorescence; LCA, Leber congenital amaurosis; OCT, optical coherence tomography.

engineered mouse models. Both adeno-associated virus serotype 5 (AAV5) and recombinant adeno-associated virus serotype $2 / 8$ (AAV 2/8) vectors carrying animal and human complementary DNA (cDNA), respectively, have been shown to rescue retinal function and preserve cone photoreceptors in RetGC1 knock-out mouse models. ${ }^{29-31}$ Moreover, an AAV8 based-gene replacement therapy, using the tyrosine capsid mutant AAV8(Y733F), has been shown to restore both useful cone and rod-mediated vision in a RetGC1/RetGC2 double knock-out mouse. ${ }^{32}$ These successful animal studies combined with the relative outer retinal preservation observed in patients with GUCY2D-LCA has resulted in advanced preparation for a human gene therapy trial.

\section{RPE65-associated LCA}

RPE65-associated LCA/EOSRD accounts for approximately $5 \%-10 \%$ of cases and has been the subject of the most clinical trials to date. ${ }^{9} \mathrm{RPE} 65$ encodes a $65 \mathrm{kD}$ retinoid isomerase expressed in the RPE; a critical component of the retinoid (visual) cycle. ${ }^{33} 34$ As such, patients with RPE65 deficiency have a lack of 11-cis-retinal. Most children with RPE65 deficiency have an EOSRD phenotype with profound night blindness from birth but residual cone-mediated vision and often mild if any nystagmus. It has been suggested that cone photoreceptors have an alternative supply of 11-cis-retinal independent of RPE65, thus allowing cone-mediated vision in younger patients. ${ }^{35}$ However, due to the 11-cis-retinal deficiency in rod photoreceptors there is early and profound nyctalopia.

OCT studies have demonstrated relatively normal retinal thickness in some patients; with more commonly a central macular area of relatively preserved retina with a ring of thinning or more widespread retinal loss. There appears to be no clear relationship between age and thinning in the first three decades. ${ }^{36}{ }^{37}$ This phenotypic variability irrespective of age, and varying both between and within families, is typical of the marked heterogeneity characterising IRD as a whole. RPE65-deficiency is also associated with reduced or absent autofluorescence on fundus autofluorescence imaging, suggesting low or absent levels of lipofuscin in the RPE. ${ }^{38}$

In 2001, Acland et al described successful gene therapy in Briard dogs with RPE65-retinopathy using subretinal delivery of recombinant adeno-associated virus serotype 2 (AAV2) vector with canine RPE65 cDNA under the control of the cytomegalovirus chicken beta actin promoter. ${ }^{39}$ Injected eyes of these dogs showed improved ERG, pupillometry and flash evoked cortical potentials in the dark-adapted state. Furthermore, these improvements were sustained for over 10 years. ${ }^{39} 40$ Subsequently, murine models of RPE65 deficiency have been characterised and rescued using gene replacement therapy, with significant improvement in visual function in both RPE $65^{-/-}$mice and naturally occurring RPE65 mutant mice (Rd12 mouse) and the demonstration of a dose-response relationship. ${ }^{3641-44}$

Success in canine and murine models ${ }^{39} 45$ resulted in four phase 1 gene therapy clinical trials in humans in close succession. ${ }^{2-4} 46$ The 2 to 5 -year follow-up data on all four trials has been very encouraging, showing the intervention to be safe with varying levels of efficacy noted; however, most studies at later intervals have shown a lack of durability of the improvements, with continuing retinal degeneration even in patients with improved retinal function. ${ }^{46-49}$ Of the 12 patients enrolled in the UK trial, an initial improvement in retinal sensitivity, darkadapted perimetry and vision-guided mobility was noted in six, five and three patients, respectively. This improvement was not sustained, with only two patients having residual improvement greater than preinterventional levels, 3 years following subretinal injection. ${ }^{47}$ Similar results were noted in the other three clinical trials, with Testa et al reporting sustained improvement in visual acuity, visual field, nystagmus frequency and pupillometry at 3 years. ${ }^{48}$ Weleber et al noted variable improvement in one or more parameters of visual function in 9 of 12 patients. ${ }^{46}$ Jacobson et al described visual function improved in all 15 patients, to different degrees, with improvements being localised to treated areas, but a waning of improvement over time and continued retinal degeneration. ${ }^{49}$ It has been proposed that continued retinal degeneration may be due to suboptimal RPE65 expression in the human retina, resulting in subsequent work to optimise the vector, promoter and transgene hoping to result in more durable benefit. ${ }^{4750}$

Acknowledging the known impaired structural properties of the visual pathway observed in visually deprived animals ${ }^{51}$ and blind human studies, ${ }^{52}$ Ashtari et al investigated the plasticity of the visual system following retinal gene therapy in patients with RPE65-LCA using non-invasive multimodal neuroimaging. ${ }^{53}$ 
They reported improvements and normalisation in the visual pathway corresponding to the retinal injection areas in the treated eyes, which were maintained over time, compared with the visual pathway for the untreated eyes which continued to deteriorate. This would support the belief that early intervention would be most likely to result in the greatest benefit. However, of note the 10 subjects in this study were aged 9 to 45 years, suggesting that intervention in adulthood could still be beneficial.

Furthermore, recently, one phase III trial (NCT00999609) and a phase I/II trial (NCT01496040) have been completed with another two phase I/II trials (clinicaltrials.gov identifiers: NCT02781480, NCT00821340,) now underway.

Pharmacological intervention has also been investigated to potentially overcome the biochemical blockade, following successful rescue in animal models. ${ }^{5455} \mathrm{~A}$ phase I/II clinical trial examining the efficacy of the synthetic prodrug QLT091001, a precursor to 9-cis-retinal, has been conducted in 18 patients (13 with RPE65-LCA and five with LRAT-LCA —as both encoded proteins participate in the retinoid cycle (figure 1)). ${ }^{56}$ Patients received a once-daily oral dose of $40 \mathrm{mg} / \mathrm{m}^{2} /$ day for 7 consecutive days. Following this, $44 \%$ of patients had a $>20 \%$ increase in isopter area in one or both eyes, as assessed by Goldmann visual field testing, and $67 \%$ of patients showed a $>5$ ETDRS letter score increase in one or both eyes. ${ }^{56} \mathrm{~A}$ phase III trial is due to commence in the near future.

\section{AIPL1-associated LCA}

AIPL1 encodes Aryl-hydrocarbon-interacting-protein-like 1-a photoreceptor-specific cochaperone that interacts specifically with the molecular chaperone HSP90 to modulate the stability of and assembly of the HSP90 substrate, retinal cGMP phosphodiesterase. ${ }^{5758}$

Sequence variants in AIPL1 are associated with a relatively severe congenital LCA phenotype, with severe and rapidly progressive visual loss, accounting for less than 5\% of LCA. ${ }^{959} 60$ Aboshiha et al investigated a worldwide cohort of 42 molecularly confirmed patients, collecting data on demographics, visual acuity, fundus examination, OCT findings and genotype. This study identified p.W278X (c.834G>A) as the most common AIPL1 variant, occurring in at least one allele in $62 \%$ of patients. ${ }^{61}$ Interestingly, hand-held OCT imaging identified four patients (three of whom harboured the aforementioned common variant) with relative preservation of central outer retinal structure, all of whom were younger than 4 years of age. ${ }^{61}$

Gene replacement therapy using an AAV2/8 vector in an AIPL1 knock-out mouse model has been shown to result in restoration of cellular function with photoreceptor cell preservation and improved retinal function, despite the severe rapidly progressive early-onset retinal degeneration seen in this mouse model. ${ }^{62}$ The early visual loss to perception of light or worse, the high-resolution OCT evidence of retained outer retinal structure early in life and the successfully treated animal models, raise the possibility of a gene therapy-based approach in AIPL1-LCA early in life; with a human clinical interventional study being in the advanced stages of development.

\section{RPGRIP1-associated LCA}

RPGRIP1-LCA is believed to be responsible for approximately $5 \%$ of cases. ${ }^{63}{ }^{64}$ RPGRIP1 is a binding partner of retinitis pigmentosa GTPase regulator (RPGR) and is essential for anchoring RPGR at the connecting cilia between the inner and outer segments of photoreceptor cells. ${ }^{65-69}$
In contrast to other forms of LCA, RPGRIP1-LCA appears to be relatively non-progressive, following an initial rapid decline in visual function. ${ }^{18}$ Furthermore, photoreceptors in the central retina appear to remain present for a significant period following deterioration of visual function. ${ }^{70}$ These features suggest a wide window of opportunity for potential intervention.

An RPGRIP1 knock-out mouse and RPGRIP1 deficient mouse and dog models have been characterised and have provided models for preclinical gene replacement studies. ${ }^{55-57}$ In RPGRIP1 knock-out mice, both improved outer segment morphology and photoreceptor survival, and better preservation of ERG responses have been demonstrated with RPGRIP1 gene replacement using both AAV2 and AAV8 vectors. ${ }^{7172}$ Improved photoreceptor function up to 24 months postsubretinal injection has also been shown in the canine model. $^{73}$

\section{CRB1-associated LCA}

Disease-causing sequence variants in CRB1 have been identified in a broad range of phenotypes, including the earlyonset disorders LCA/EOSRD and retinitis pigmentosa with and without a Coats-like vasculopathy, a later-onset macular dystrophy and isolated autosomal recessive foveal retinoschisis. ${ }^{7-77}$ Approximately 10\% of LCA/EOSRD patients harbour variants in CRB1. ${ }^{918}$ The CRB1 protein is known to colocalise with the zonula adherens, forming a major component of the outer limiting membrane and is believed to have a role in retinal development.

Both the severity and rate of progression vary significantly between patients with CRB1-associated LCA/EOSRD, with clinical examination and OCT findings often allowing directed molecular screening of CRB1. ${ }^{74} 78$ Characteristic findings include macular atrophy, nummular pigmentation, relative para-arteriolar preservation of the RPE and retinal thickening with loss of lamination-in direct contrast to other forms of LCA/EOSRD where progressive retinal thinning is commonplace.

\section{CEP290-associated LCA}

CEP290-LCA/EOSRD accounts for 15\%-20\% of cases, thereby representing one of the most common genetic causes. ${ }^{17}$ CEP290 localises to the centromeres and the connecting cilia of photoreceptors. The intronic variant c. $2991+1655 \mathrm{~A}>\mathrm{G}$ is the most common disease-causing mutation (especially in European countries and in the USA), having been identified in at least one allele in $77 \%$ of patients $(n=43)$ in a study of CEP290-LCA. ${ }^{79}$

Retinal examination can be relatively normal in infancy with significant variability in visual function, with no correlation between age and visual acuity (VA) noted over an average follow-up period of 10 years; although severe VA loss (counting fingers or worse) is seen in most, but not all, children in the first decade. ${ }^{177980}$

Interestingly, OCT studies have shown that despite profound cone dysfunction, the foveal outer nuclear layer (cone nuclei) is structurally detectable until the fourth decade of life in some patients, although with abnormal inner and outer segments in contrast to the early loss of rod photoreceptors. ${ }^{81}$ These findings suggest a potential window of opportunity-wider for possible cone rescue than rod. Gene therapy-based intervention has been explored in vitro with a lentiviral vector containing human CEP290 and been shown to effectively transduce patient-specific induced pluripotent 
stem cell-derived photoreceptor precursor cells and rescue the cellular phenotype. ${ }^{82}$ Other molecular therapeutic avenues being explored focus on the common deep intronic CEP290 sequence variant, which creates a strong splice donor site that leads to the insertion of a cryptic exon encoding a premature stop codon. Several approaches have been suggested, including the use of antisense oligonucleotide-mediated exon skipping to abrogate the disease-causing variant or correction of the splice defect using CRISPR/Cas9-mediated gene editing. ${ }^{83} 84$ Both of these novel approaches show promise and human clinical trials are anticipated in the near future. ${ }^{85}$

\section{RDH12-associated LCA}

Disease-causing sequence variants in $R D H 12$ are identified in up to approximately $10 \%$ of LCA/EOSRD patients. ${ }^{9}{ }^{19} \mathrm{RDH} 12$ encodes retinol dehydrogenase 12 , a component of the visual cycle, which when deficient is believed to result in retinal toxicity secondary to all-trans-retinal accumulation. ${ }^{86}$

Most patients with biallelic RDH12 mutations have an EOSRD rather than LCA phenotype. There is a recognisable fundus phenotype with widespread RPE and retinal atrophy and minimal intraretinal pigmentation in early childhood, with dense intraretinal bone-spicule pigmentation developing over time (figure 2). ${ }^{19}$ There is early progressive macular atrophy, with pigmentation and yellowing and corresponding macular excavation on OCT and loss of fundus autofluorescence. ${ }^{19}$

Promising results of AAV2/8-vector-mediated $\mathrm{RDH} 12$ gene replacement therapy in $R d h 12$ knock-out mice has raised the possibility of human clinical trials in the future. ${ }^{87}$

\section{LRAT-associated LCA}

LRAT encodes Lecithin:retinol acyl transferase, a key enzyme in the vitamin A recycling pathway (visual cycle), with LRAT deficiency associated with a similar phenotype to RPE65-deficiency, although being far less common. ${ }^{98}$ As described for RPE65-deficiency, the synthetic prodrug QLT091001, a precursor to 9-cis-retinal, has been shown in a phase I trial to improve VA and kinetic visual fields in LRAT-LCA, with a phase III trial anticipated in the future.

\section{Therapeutic advances potentially applicable to advanced LCA}

Stem cell therapies hold great promise for the future to restore lost retinal cells in advanced disorders, including potentially LCA. At present, human stem cell therapy has primarily been confined to RPE transplantation, with two phase I/II studies reporting safe transplantation of human embryonic stem cell-derived RPE and induced pluripotent stem cell-derived RPE, respectively. ${ }^{89}{ }^{90}$ However, transplantation of other retinal cells, including photoreceptors-which would be needed in LCA, remains at a preclinical stage.

Clinical trials have also been conducted to investigate the therapeutic potential of electronic retinal prostheses in advanced retinal degeneration including choroideremia and retinitis pigmentosa. At present, current epiretinal or subretinal devices cannot sufficiently replace the high density of photoreceptors at the fovea and have thereby resulted in very low levels of VA improvement in a minority of patients, with a varied safety profile. $^{91-93}$

\section{CONCLUSIONS}

Improvements in molecular genetic testing and clinical assessments (primarily quantitative high-resolution retinal imaging) have led to a greater understanding of genotype-phenotype correlations and structure-function associations in LCA/ EOSRD. This coupled with advances in gene therapy in both animal model studies and human clinical trials have resulted in a current new era of increasing clinical trials for multiple genetic subtypes of LCA/EOSRD and the cautious optimism for the development of proven successful and durable treatments which both improve visual function and halt/markedly slow retinal degeneration. Substantial challenges remain however, particularly for patients with severe visual loss from birth where normal visual pathway function has never been established, with intervention likely needed very early in infancy to fully address any potential cortical limitations and thereby optimise outcomes.

Acknowledgements The authors wish to thank Melissa Kasilian who assisted with the figures.

Contributors NK drafted the manuscript and provided critical revision. MM conceived and supervised the manuscript and provided critical revision. ATM and RGW provided critical revision of the manuscript.

Funding Supported by grants from the National Institute for Health Research Biomedical Research Centre at Moorfields Eye Hospital National Health Service Foundation Trust and UCL Institute of Ophthalmology (UK), Fight For Sight (UK), Moorfields Eye Hospital Special Trustees (UK), Moorfields Eye Charity (UK), the Foundation Fighting Blindness (FFB, USA), Retinitis Pigmentosa Fighting Blindness (UK), and the Wellcome Trust (099173/Z/12/Z) (UK). Michel Michaelides is a recipient of an FFB Career Development Award.

Disclaimer The funding organisations had no role in the design or conduct of this research.

Competing interests None declared.

Patient consent Detail has been removed from this case description/these case descriptions to ensure anonymity. The editors and reviewers have seen the detailed information available and are satisfied that the information backs up the case the authors are making.

Provenance and peer review Not commissioned; externally peer reviewed.

Open Access This is an Open Access article distributed in accordance with the terms of the Creative Commons Attribution (CC BY 4.0) license, which permits others to distribute, remix, adapt and build upon this work, for commercial use, provided the original work is properly cited. See: http://creativecommons.org/licenses/by/4.0/

(C) Article author(s) (or their employer(s) unless otherwise stated in the text of the article) 2017. All rights reserved. No commercial use is permitted unless otherwise expressly granted.

\section{REFERENCES}

1 Liew G, Michaelides M, Bunce C. A comparison of the causes of blindness certifications in England and Wales in working age adults (16-64 years), 1999-2000 with 2009-2010. BMJ Open 2014;4:e004015.

2 Bainbridge JW, Smith AJ, Barker SS, et al. Effect of gene therapy on visual function in Leber's congenital amaurosis. N Eng/ J Med 2008;358:2231-9.

3 Maguire AM, Simonelli F, Pierce EA, et al. Safety and efficacy of gene transfer for Leber's congenital amaurosis. N Engl J Med 2008;358:2240-8.

4 Hauswirth WW, Aleman TS, Kaushal S, et al. Treatment of leber congenital amaurosis due to RPE65 mutations by ocular subretinal injection of adeno-associated virus gene vector: short-term results of a phase I trial. Hum Gene Ther 2008;19:979-90.

5 Perrault I, Rozet JM, Gerber S, et al. Leber congenital amaurosis. Mol Genet Metab 1999;68:200-8.

6 Leber T, Netzhaut DKder. In. Saemish T, ed. Graefe Handbuch der gesamten Augenheilkunde. 2nd ed. Leipzig, Germany:W. Engelman, 1916:1076-225.

7 Weleber RG, Michaelides M, Trzupek KM, et al. The phenotype of Severe Early Childhood Onset Retinal Dystrophy (SECORD) from mutation of RPE65 and differentiation from Leber congenital amaurosis. Invest Ophthalmol Vis Sci 2011;52:292-302.

8 RetNet. RetNet Summaries. Secondary RetNet Summaries 30 oct 2015. 2015 https:// sph.uth.edu/retnet/sum-dis.htm

9 den Hollander Al, Roepman R, Koenekoop RK, et al. Leber congenital amaurosis: genes, proteins and disease mechanisms. Prog Retin Eye Res 2008;27:391-419.

10 Astuti GD, Bertelsen M, Preising MN, et al. Comprehensive genotyping reveals RPE65 as the most frequently mutated gene in Leber congenital amaurosis in Denmark. Eur $J$ Hum Genet 2016;24.

11 Wang H, Wang X, Zou X, et al. Comprehensive molecular diagnosis of a large chinese Leber Congenital Amaurosis Cohort. Invest Ophthalmol Vis Sci 2015;56:3642-55. 
12 Koenekoop RK. An overview of Leber congenital amaurosis: a model to understand human retinal development. Surv Ophthalmol 2004;49:379-98.

13 Stone EM. Leber congenital amaurosis - a model for efficient genetic testing of heterogeneous disorders: Ixiv Edward Jackson Memorial Lecture. Am J Ophthalmol 2007; 144:791-811.

14 Heher KL, Traboulsi El, Maumenee IH. The natural history of Leber's congenital amaurosis. Age-related findings in 35 patients. Ophthalmology 1992;99:241-5.

15 Sonksen PM, Dale N. Visual impairment in infancy: impact on neurodevelopmental and neurobiological processes. Dev Med Child Neurol 2002;44:782-91.

16 Perrault I, Rozet JM, Gerber S, et al. Spectrum of retGC1 mutations in Leber's congenital amaurosis. Eur J Hum Genet 2000;8:578-82.

17 den Hollander Al, Koenekoop RK, Yzer S, et al. Mutations in the CEP290 (NPHP6) gene are a frequent cause of Leber congenital amaurosis. Am J Hum Genet 2006;79:556-61.

18 Hanein S, Perrault I, Gerber S, et al. Leber congenital amaurosis: comprehensive survey of the genetic heterogeneity, refinement of the clinical definition, and genotype-phenotype correlations as a strategy for molecular diagnosis. Hum Mutat 2004;23:306-17.

19 Mackay DS, Dev Borman A, Moradi P, et al. RDH12 retinopathy: novel mutations and phenotypic description. Mol Vis 2011;17:2706-16.

20 Drivas TG, Holzbaur EL, Bennett J. Disruption of CEP290 microtubule/membranebinding domains causes retinal degeneration. J Clin Invest 2013;123:4525-39.

21 Khan AO, Bolz HJ, Bergmann C. Early-onset severe retinal dystrophy as the initial presentation of IFT140-related skeletal ciliopathy. J Aapos 2014;18:203-5.

22 Estrada-Cuzcano A, Koenekoop RK, Coppieters F, et al. IQCB1 mutations in patients with leber congenital amaurosis. Invest Ophtha/mo/ Vis Sci 2011:52:834-9.

23 Dizhoor AM, Lowe DG, Olshevskaya EV, et al. The human photoreceptor membrane guanylyl cyclase, RetGC, is present in outer segments and is regulated by calcium and a soluble activator. Neuron 1994;12:1345-52.

24 Liu X, Seno K, Nishizawa Y, et al. Ultrastructural localization of retinal guanylate cyclase in human and monkey retinas. Exp Eye Res 1994;59:761-8.

25 Jacobson SG, Cideciyan AV, Peshenko IV, et al. Determining consequences of retinal membrane guanylyl cyclase (RetGC1) deficiency in human Leber congenital amaurosis en route to therapy: residual cone-photoreceptor vision correlates with biochemical properties of the mutants. Hum Mol Genet 2013;22:168-83.

26 Pasadhika S, Fishman GA, Stone EM, et al. Differential macular morphology in patients with RPE65-, CEP290-, GUCY2D-, and AIPL1-related Leber congenital amaurosis. Invest Ophthalmol Vis Sci 2010;51:2608-14.

27 Boye SE. Leber Congenital Amaurosis caused by mutations in GUCY2D. Cold Spring Harb Perspect Med 2015;5:a017350.

28 Williams ML, Coleman JE, Haire SE, et al. Lentiviral expression of retinal guanylate cyclase-1 (RetGC1) restores vision in an avian model of childhood blindness. PLoS Med 2006;3:e201.

29 Haire SE, Pang J, Boye SL, et al. Light-driven cone arrestin translocation in cones of postnatal guanylate cyclase- 1 knockout mouse retina treated with AAV-GC1. Invest Ophthalmol Vis Sci 2006:47:3745-53.

30 Boye SE, Boye SL, Pang J, et al. Functional and behavioral restoration of vision by gene therapy in the guanylate cyclase-1 (GC1) knockout mouse. PLoS One 2010;5:e11306.

31 Mihelec M, Pearson RA, Robbie SJ, et al. Long-term preservation of cones and improvement in visual function following gene therapy in a mouse model of leber congenital amaurosis caused by guanylate cyclase-1 deficiency. Hum Gene Ther 2011;22:1179-90.

32 Boye SL, Peshenko IV, Huang WC, et al. AAV-mediated gene therapy in the guanylate cyclase (RetGC1/RetGC2) double knockout mouse model of Leber congenital amaurosis. Hum Gene Ther 2013:24:189-202.

33 Redmond TM, Poliakov E, Yu S, et al. Mutation of key residues of RPE65 abolishes its enzymatic role as isomerohydrolase in the visual cycle. Proc Natl Acad Sci U SA 2005; 102:13658-63

34 Moiseyev G, Chen Y, Takahashi Y, et al. RPE65 is the isomerohydrolase in the retinoid visual cycle. Proc Natl Acad Sci U S A 2005;102:12413-8.

35 Znoiko SL, Crouch RK, Moiseyev G, et al. Identification of the RPE65 protein in mammalian cone photoreceptors. Invest Ophthalmol Vis Sci 2002;43:1604-9.

36 Jacobson SG, Aleman TS, Cideciyan AV, et al. Identifying photoreceptors in blind eyes caused by RPE65 mutations: prerequisite for human gene therapy success. Proc Natl Acad Sci U S A 2005:102:6177-82.

37 Maeda T, Cideciyan AV, Maeda A, et al. Loss of cone photoreceptors caused by chromophore depletion is partially prevented by the artificial chromophore pro-drug, 9-cis-retinyl acetate. Hum Mol Genet 2009:18:2277-87.

38 Lorenz B, Wabbels B, Wegscheider E, et al. Lack of fundus autofluorescence to 488 nanometers from childhood on in patients with early-onset severe retinal dystrophy associated with mutations in RPE65. Ophthalmology 2004;111:1585-94.

39 Acland GM, Aguirre GD, Ray J, et al. Gene therapy restores vision in a canine model of childhood blindness. Nat Genet 2001;28:92-5

40 Cideciyan AV, Jacobson SG, Beltran WA, et al. Human retinal gene therapy for Leber congenital amaurosis shows advancing retinal degeneration despite enduring visual improvement. Proc Natl Acad Sci U SA 2013;110:E517-E525.

41 Redmond TM, Yu S, Lee E, et al. Rpe65 is necessary for production of 11-cis-vitamin A in the retinal visual cycle. Nat Genet 1998;20:344-50.
42 Pang JJ, Chang B, Hawes NL, et al. Retinal degeneration 12 (rd12): a new, spontaneously arising mouse model for human Leber congenital amaurosis (LCA) Mol Vis 2005; 11:152-62.

43 Pang JJ, Chang B, Kumar A, et al. Gene therapy restores vision-dependent behavior as well as retinal structure and function in a mouse model of RPE65 Leber congenital amaurosis. Mol Ther 2006;13:565-72.

44 Roman AJ, Boye SL, Aleman TS, et al. Electroretinographic analyses of Rpe65-mutant rd12 mice: developing an in vivo bioassay for human gene therapy trials of Leber congenital amaurosis. Mol Vis 2007;13:1701-10.

45 Bemelmans AP, Kostic C, Crippa SV, et al. Lentiviral gene transfer of RPE65 rescues survival and function of cones in a mouse model of Leber congenital amaurosis. PLOS Med 2006;3:e347.

46 Weleber RG, Pennesi ME, Wilson DJ, et al. Results at 2 years after gene therapy for RPE65-deficient leber congenital amaurosis and severe early-childhood-onset retinal dystrophy. Ophthalmology 2016;123:1606-20.

47 Bainbridge JW, Mehat MS, Sundaram V, et al. Long-term effect of gene therapy on Leber's congenital amaurosis. N Engl J Med 2015;372:1887-97.

48 Testa F, Maguire AM, Rossi S, et al. Three-year follow-up after unilateral subretinal delivery of adeno-associated virus in patients with Leber congenital Amaurosis type 2. Ophthalmology 2013;120:1283-91.

49 Jacobson SG, Cideciyan AV, Roman AJ, et al. Improvement and decline in vision with gene therapy in childhood blindness. N Engl J Med 2015;372:1920-6.

50 Georgiadis A, Duran Y, Ribeiro J, et al. Development of an optimized AAV2/5 gene therapy vector for Leber congenital amaurosis owing to defects in RPE65. Gene Ther 2016;23:857-62

51 Dürsteler MR, Garey LJ, Movshon JA. Reversal of the morphological effects of monocular deprivation in the kittens's lateral geniculate nucleus. J Physiol 1976:261:189-210.

52 Pan WJ, Wu G, Li CX, Cx L, et al. Progressive atrophy in the optic pathway and visual cortex of early blind Chinese adults: a voxel-based morphometry magnetic resonance imaging study. Neuroimage 2007;37:212-20.

53 Ashtari M, Zhang H, Cook PA, et al. Plasticity of the human visual system after retinal gene therapy in patients with Leber's congenital amaurosis. Sci Trans/ Med 2015;7:296ra110.

54 Van Hooser JP, Liang Y, Maeda T, et al. Recovery of visual functions in a mouse model of Leber congenital amaurosis. J Biol Chem 2002;277:19173-82.

55 Maeda T, Dong Z, Jin H, et al. QLT091001, a 9-cis-retinal analog, is welltolerated by retinas of mice with impaired visual cycles. Invest Ophthalmol Vis Sci 2013;54:455-66.

56 Scholl HP, Moore AT, Koenekoop RK, et al. Safety and proof-of-concept study of oral QLT091001 in retinitis pigmentosa due to inherited deficiencies of retinal pigment epithelial 65 protein (RPE65) or lecithin:retinol acyltransferase (LRAT). PLoS One 2015; 10:e0143846

57 Hidalgo-de-Quintana J, Evans RJ, Cheetham ME, et al. The Leber congenital amaurosis protein AIPL1 functions as part of a chaperone heterocomplex. Invest Ophthalmol Vis Sci 2008:49:2878-87.

58 Kolandaivelu S, Huang J, Hurley JB, et al. AIPL1, a protein associated with childhood blindness, interacts with alpha-subunit of rod phosphodiesterase (PDE6) and is essential for its proper assembly. J Biol Chem 2009;284:30853-61.

59 Bellingham J, Davidson AE, Aboshiha J, et al. Investigation of aberrant splicing induced by AIPL1 variations as a cause of Leber Congenital Amaurosis. Invest Ophthalmol Vis Sci 2015;56:7784-93.

60 Tan MH, Mackay DS, Cowing J, et al. Leber congenital amaurosis associated with AIPL1: challenges in ascribing disease causation, clinical findings, and implications for gene therapy. PLoS One 2012;7:e32330.

61 Aboshiha J, Dubis AM, van der Spuy J, et al. Preserved outer retina in AIPL 1 Leber's congenital amaurosis: implications for gene therapy. Ophthalmology 2015;122:862-4.

62 Tan MH, Smith AJ, Pawlyk B, et al. Gene therapy for retinitis pigmentosa and Leber congenital amaurosis caused by defects in AIPL1: effective rescue of mouse models of partial and complete Aipl 1 deficiency using AAV2/2 and AAV2/8 vectors. Hum Mol Genet 2009;18:2099-114

63 Gerber S, Perrault I, Hanein S, et al. Complete exon-intron structure of the RPGRinteracting protein (RPGRIP1) gene allows the identification of mutations underlying Leber congenital amaurosis. Eur J Hum Genet 2001;9:561-71.

64 Dryja TP, Adams SM, Grimsby JL, et al. Null RPGRIP1 alleles in patients with Leber congenital amaurosis. Am J Hum Genet 2001;68:1295-8.

65 Zhao Y, Hong DH, Pawlyk B, et al. The retinitis pigmentosa GTPase regulator (RPGR)- interacting protein: subserving RPGR function and participating in disk morphogenesis. Proc Natl Acad Sci U S A 2003:100:3965-70.

66 Pelletier V, Jambou M, Delphin N, et al. Comprehensive survey of mutations in RP2 and RPGR in patients affected with distinct retinal dystrophies: genotype-phenotype correlations and impact on genetic counseling. Hum Mutat 2007;28:81-91.

67 Boylan JP, Wright AF. Identification of a novel protein interacting with RPGR. Hum Mol Genet 2000:9:2085-93.

68 Lu X, Ferreira PA. Identification of novel murine- and human-specific RPGRIP1 splice variants with distinct expression profiles and subcellular localization. Invest Ophthalmol Vis Sci 2005;46:1882-90 
69 Li T. Leber congenital amaurosis caused by mutations in RPGRIP1. Cold Spring Harb Perspect Med 2015;5(4):a017384.

70 Jacobson SG, Cideciyan AV, Aleman TS, et al. Leber congenital amaurosis caused by an RPGRIP1 mutation shows treatment potential. Ophthalmology 2007;114:895-8.

71 Pawlyk BS, Smith AJ, Buch PK, et al. Gene replacement therapy rescues photoreceptor degeneration in a murine model of Leber congenital amaurosis lacking RPGRIP. Invest Ophthalmol Vis Sci 2005;46:3039-45.

72 Pawlyk BS, Bulgakov OV, Liu X, et al. Replacement gene therapy with a human RPGRIP1 sequence slows photoreceptor degeneration in a murine model of Leber congenital amaurosis. Hum Gene Ther 2010;21:993-1004.

73 Lhériteau E, Petit L, Weber M, et al. Successful gene therapy in the RPGRIP1-deficient dog: a large model of cone-rod dystrophy. Mol Ther 2014;22:265-77.

74 Henderson RH, Mackay DS, Li Z, et al. Phenotypic variability in patients with retinal dystrophies due to mutations in CRB1. Br J Ophthalmol 2011;95:811-7.

75 Simonelli F, Ziviello C, Testa F, et al. Clinical and molecular genetics of Leber's congenital amaurosis: a multicenter study of Italian patients. Invest Ophthalmol Vis Sci 2007:48:4284-90.

76 Tsang SH, Burke T, Oll M, et al. Whole exome sequencing identifies CRB1 defect in an unusual maculopathy phenotype. Ophthalmology 2014;121:1773-82

77 Wolfson Y, Applegate CD, Strauss RW, et al. CRB1-related maculopathy with cystoid macular edema. JAMA Ophthalmol 2015;133:1357-60.

78 Kousal B, Dudakova L, Gaillyova R, et al. Phenotypic features of CRB1-associated early-onset severe retinal dystrophy and the different molecular approaches to identifying the disease-causing variants. Graefes Arch Clin Exp Ophthalmol 2016:254:1833-9.

79 McAnany JJ, Genead MA, Walia S, et al. Visual acuity changes in patients with leber congenital amaurosis and mutations in CEP290. JAMA Ophthalmol 2013;131:178-82.

80 Perrault I, Delphin N, Hanein S, et al. Spectrum of NPHP6/CEP290 mutations in Leber congenital amaurosis and delineation of the associated phenotype. Hum Mutat 2007;28:416.

81 Cideciyan AV, Rachel RA, Aleman TS, et al. Cone photoreceptors are the main targets for gene therapy of NPHP5 (IQCB1) or NPHP6 (CEP290) blindness: generation of an all-cone Nphp6 hypomorph mouse that mimics the human retinal ciliopathy. Hum $\mathrm{Mo}$ Genet 2011;20:1411-23.

82 Burnight ER, Wiley LA, Drack AV, et al. CEP290 gene transfer rescues Leber congenital amaurosis cellular phenotype. Gene Ther 2014:21:662-72.

83 Maeder ML, Gersbach CA. Genome-editing technologies for gene and cell therapy. Mol Ther 2016:24:430-46.

84 Veltrop M, Aartsma-Rus A. Antisense-mediated exon skipping: taking advantage of a trick from Mother Nature to treat rare genetic diseases. Exp Cell Res 2014:325:50-5.

85 Parfitt DA, Lane A, Ramsden CM, et al. Identification and correction of mechanisms underlying inherited Blindness in Human iPSC-Derived Optic Cups. Cell Stem Cell 2016:18:769-81.

86 Parker RO, Crouch RK, dehydrogenases R. RDHs) in the visual cycle. Experimental eye research 2010:91:788-92.

87 Thompson DA, Jia L, Yao J, et al. AAV-mediated expression of human Rdh12 in mouse Retina. Investigative Ophthalmology \& Visual Science 2012;53:1916-16

88 Dev Borman A, Ocaka LA, Mackay DS, et al. Early onset retinal dystrophy due to mutations in LRAT: molecular analysis and detailed phenotypic study. Invest Ophthalmol Vis Sci 2012:53:3927-38.

89 Schwartz SD, Tan G, Hosseini H, et al. Subretinal transplantation of embryonic stem cell-derived retinal pigment epithelium for the treatment of macular degeneration: an assessment at 4 years. Invest Ophthalmol Vis Sci 2016;579:ORSFc1-9.

90 Mandai $\mathrm{M}$, Watanabe $\mathrm{A}$, Kurimoto $\mathrm{Y}$, et al. Autologous induced stem-cell-derived retinal cells for macular degeneration. N Engl J Med 2017:376:1038-46.

91 Barry MP, Dagnelie G; Argus II Study Group. Use of the Argus II retinal prosthesis to improve visual guidance of fine hand movements. Invest Ophthalmol Vis Sci 2012;53:5095-101

92 Klauke S, Goertz M, Rein S, et al. Stimulation with a wireless intraocular epiretina implant elicits visual percepts in blind humans. Invest Ophthalmo/ Vis $\mathrm{SCl}$ 2011:52:449-55.

93 Zrenner E. Fighting blindness with microelectronics. Sci Trans/ Med 2013;5:210ps16

94 Zeitz C, Robson AG, Audo I. Congenital stationary night blindness: an analysis and update of genotype-phenotype correlations and pathogenic mechanisms. Prog Retin Eye Res 2015;45:58-110 


\section{Correction: Leber congenital amaurosis/early-onset severe retinal dystrophy: clinical features, molecular genetics and therapeutic interventions}

Kumaran N, Moore AT, Weleber RG, et al. Leber congenital amaurosis/early-onset severe retinal dystrophy: clinical features, molecular genetics and therapeutic interventions. $\mathrm{Br} J$ Ophthalmol 2017;101:1147-54. doi: 10.1136/bjophthalmol-2016-309975.

The authors wish to correct the legend of table 1 . It reads: *Genes associated with EOSRD. †Genes more frequently associated with LCA. However it should read: †Genes associated with EOSRD. *Genes more frequently associated with LCA.

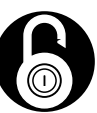

\section{OPEN ACCESS}

Open access This is an Open Access article distributed in accordance with the Creative Commons Attribution Non Commercial (CC BY 4.0) license, which permits others to distribute, remix, adapt, build upon this work non-commercially, and license their derivative works on different terms, provided the original work is properly cited and the use is noncommercial. See: http://creativecommons.org/licenses/by/4.0/

(C) Author(s) (or their employer(s)) 2019. Re-usepermitted under CC BY. Published by BMJ.

Br J Ophthalmol 2019;103:862. doi:10.1136/bjophthalmol-2016-309975corr1

D Check for updates 